\title{
Genotypic Characterization of
} Mycobacterium bovis Isolates From Dairy Cattle Diagnosed With Clinical Tuberculosis

\author{
Elizabeth Hortêncio de Melo ${ }^{1}$, Harrison Magdinier Gomes ${ }^{2 *}$, Philip Noel Suffys ${ }^{2}$, \\ Márcia Quinhones Pires Lopes ${ }^{2}$, Raquel Lima de Figueiredo Teixeira ${ }^{2}$, \\ ícaro Rodrigues dos Santos ${ }^{2}$, Marilia Masello Junqueira Franco ${ }^{3}$, Helio Langoni ${ }^{3}$, \\ Antonio Carlos Paes ${ }^{3}$, José Augusto Bastos Afonso ${ }^{4}$ and Carla Lopes de Mendonça ${ }^{4}$ \\ 'Programa de Pós-Graduação em Medicina Veterinária, Universidade Federal Rural de Pernambuco, Recife, Brazil, \\ ${ }^{2}$ Laboratório de Biologia Molecular Aplicada à Micobactérias, Fundação Oswaldo Cruz, Laboratório de Biologia Molecular \\ Aplicada à Micobactérias, Rio de Janeiro, Brazil, ${ }^{3}$ Departamento de Higiene Veterinária e Saúde Pública, Faculdade de \\ Medicina Veterinária e Zootecnia, Universidade Estadual Paulista, Botucatu, Brazil, ${ }^{4}$ Clínica de Bovinos de Garanhuns, \\ Universidade Federal Rural de Pernambuco, Garanhuns, Brazil
}

\section{OPEN ACCESS}

Edited by:

Flabio R. Araujo,

Brazilian Agricultural Research Corporation (EMBRAPA), Brazil

Reviewed by:

Martín José Zumárraga, Instituto Nacional de Tecnología Agropecuaria (Argentina), Argentina Faham Khamesipour, Shahid Beheshti University of Medical Sciences, Iran

*Correspondence: Harrison Magdinier Gomes magdinier@gmail.com

Specialty section: This article was submitted to Veterinary Infectious Diseases,

a section of the journal Frontiers in Veterinary Science

Received: 25 July 2021 Accepted: 31 August 2021 Published: 11 October 2021

Citation:

Melo EH, Gomes HM, Suffys PN, Lopes MQP, Figueiredo Teixeira RL, Santos ÍR, Franco MMJ, Langoni $H$ Paes AC, Afonso JAB and Mendonça $C L$ (2021) Genotypic Characterization of Mycobacterium bovis Isolates From

Dairy Cattle Diagnosed With Clinical Tuberculosis.

Front. Vet. Sci. 8:747226. doi: 10.3389/fvets.2021.747226
Molecular diagnosis of bovine tuberculosis plays an essential role in the epidemiological knowledge of the disease. Bovine tuberculosis caused by Mycobacterium bovis represents a risk to human health. This study aimed to perform the genotypic characterization of $M$. bovis isolated from bovines diagnosed as tuberculosis from dairy herds in the state of Pernambuco, Brazil. Granulomas from 30 bovines were sent for microbiological culture, and colonies compatible with Mycobacterium spp. were obtained in at least one culture from 17/30 granulomas. All isolates were confirmed to be $M$. bovis by spoligotyping and 24/oci MIRU-VNTR typing. While spoligotyping characterized the isolates as SB0121, SB0295, SB0852, SB0120, and an unclassified genotype, 24/oci MIRU-VNTR rendered two clusters of two isolates each and 13 unique profiles. Loci ETR-A showed higher discriminatory power, and loci (ETR-B, ETR-C, MIRU16, MIRU27, and QUB26) showed moderate allelic diversity. This is the first study on the genetic variability of the infectious agent cause of bovine TB in Pernambuco and demonstrates variability of strains in the state. Thus, it corroborates the importance of this microorganism as agent of bovine tuberculosis and its zoonotic potential, this epidemiological tool being a determinant in the rigor of the sanitary practices of disease control in dairy herds.

Keywords: bovine tuberculosis, dairy cattle, genotyping, Mycobacterium bovis, pathology, spoligotyping, MIRU-VNTR

\section{INTRODUCTION}

Bovine tuberculosis is a chronic progressive disease caused by Mycobacterium bovis which affects mainly cattle and buffalo but also infects other mammalian species of mammals, including humans (1). The zoonotic potential of this disease is related to the consumption of raw milk and unpasteurized derivatives, representing the main route of transmission to humans, more pronounced in rural areas. In the state of Pernambuco, a prevalence of outbreaks of 2.87 and $0.62 \%$ of infected animals was reported in 2016, with a tendency to concentrate in the Agreste region of the state and with a predominance in dairy properties (2). 
The interest in nucleic acid-based diagnostic procedures increased because of the limitations of conventional testing such as lack of sensitivity and specificity of the allergic-skin test and the long period for confirming the presence of the agent by bacteriological methods (3). In addition, molecular typing methods have provided a great impetus in the molecular epidemiology studies of the $M$. tuberculosis complex including comparing mycobacterial genome sequences. Among the most used genotyping techniques for the study of the M. tuberculosis complex are Spoligotyping and Variable Number of Interspersed Repetitive Units of Mycobacteria (MIRU-VNTR) (4, 5). MIRUVNTR has higher discriminatory power and has currently been the method of choice in the genotyping studies of Mycobacterium spp. and, in particular related to $M$. bovis, allows the identification of prevalent strains circulating in a herd or geographic regions $(4,5)$.

M. bovis infection has an impact on both animal and human health; non-etheless, scarce are the studies in the region on molecular genotyping. Given the lack of data on the contribution and nature of the Mycobacterium tuberculosis complex (MTBC) to bovine $\mathrm{TB}$ in the state of Pernambuco, we performed the genotypic characterization of Mycobacteria isolated from bovines from dairy herds in this region that were diagnosed clinically with tuberculosis, coming from dairy herds in the state of Pernambuco.

\section{MATERIALS AND METHODS}

The study included 28 bovines and two buffaloes that had been attended at the Bovine Clinic of Garanhuns/UFRPE, presenting clinical symptoms suggestive for tuberculosis. The animals were submitted to clinical examination, with information, including epidemiological, that was annotated in clinical records. Among the information present in the anamnesis provided by the owners, common to most animals, were progressive weight loss, dry cough, and decreased milk production.

According to the evolution/severity of the clinical cases and the result of the allergic-skin test, the animals were euthanized according to the current legislation (Brazil, Ministry of Agriculture, Livestock and Supply. Normative Instruction n. 19, 10 of October, 2016) and submitted for anatomopathological examination.

Fragments of organs with lesions characteristic of granulomas were collected for histopathological examination and lymph nodes with lesions for microbiological culture. The samples for bacteriology were stored in a freezer $\left(-80^{\circ} \mathrm{C}\right)$ for further processing, while for histopathological evaluation, fragments were fixed in $10 \%$ buffered formaldehyde, processed, and stained with hematoxylin and eosin (HE). Granulomas from all 30 animals were collected and sent for microbiological culture and sample processing, and culture conditions favoring isolation of $M$. bovis were carried out following the recommendations of Franco et al. (6). Samples were minced and decontaminated according to the Petroff method, inoculated on Löwenstein-Jensen and Stonebrink medium, and incubated at $37^{\circ} \mathrm{C}$ for 90 days.
Nucleic acid was obtained from the cells by thermolysis. Molecular identification to the Mycobacterium species was performed by PCR amplification of a 1,020-bp fragment of the gyrB gene, as described by Chimara et al. (7) and Franco et al. (6). In the reaction, $1 \mu \mathrm{l}$ of DNA (20 ng) and $47 \mu$ of Master Mix $(1 \times)$ were used (Thermo Scientific, Waltham, MA, USA), as well as $10 \mathrm{pM}$ of each of the primers MTUBf (5' TCGGACGCGTATGCGATATC $3^{\prime}$ ) and MTUBr (5' ACATACAGTTCGGACTTGCG 3') [DNA Express Biotecnologia LTDA, Brazil]. The cycling profile consisted of denaturation at $95^{\circ} \mathrm{C}$ for $10 \mathrm{~min}$, followed by 35 amplification cycles at $94^{\circ} \mathrm{C}$ for $1 \mathrm{~min}, 65^{\circ} \mathrm{C}$ for $1 \mathrm{~min}$, and $72^{\circ} \mathrm{C}$ for $1.5 \mathrm{~min}$, and a final extension at $72^{\circ} \mathrm{C}$ for $10 \mathrm{~min}$. The amplification and fragment size were confirmed by electrophoresis in agarose gel $(1 \%)$ stained with GelRed ${ }^{\mathrm{TM}}$ (Biotium, Hayward, CA, USA) using a 100-bp molecular marker (DNA Express Biotecnologia LTDA). Then, $10 \mu \mathrm{l}$ of the amplified product was submitted for restriction fragment length polymorphism (RFLP) through digestion by restriction enzymes RsaI, TaqI, and SacII (Thermo Scientific, Waltham, MA, USA), following the manufacturer's recommendations. The generated fragments were separated on $2 \%$ agarose gel stained with GelRed ${ }^{\mathrm{TM}}$ using 50- and 100-bp molecular markers (DNA Express Biotecnologia LTDA). After electrophoresis, the gels were photographed in photo-documentation equipment (2UV Transilluminator UVP) and restriction patterns compared to those described by Chimara et al. (7).

Spoligotyping was performed as described by Kamerbeek et al. (4), and the amplified products underwent membrane hybridization (manufacturing in-house) with 43 oligonucleotides. For amplification of the DR region, $20 \mu \mathrm{M}$ of each of primers DRa $5^{\prime}$ GGTTTTGGGTCTGACGAC $3^{\prime}\left(5^{\prime}\right.$ biotinylated) and DRb (5' CCGAGAGGGGACGGAAAC $3^{\prime}$ ), MyTaq Mix (12.5 $\mu \mathrm{l}), 1 \mu \mathrm{l}$ (20 ng) genomic DNA, and ultra-pure water $(9.5 \mu \mathrm{l})$ were submitted to PCR in a final volume of $25 \mu \mathrm{l}$.

MIRU-VNTR typing using a combination of 24-loci was performed according to Supply et al. (5). In each PCR reaction, 10 $\mu 1$ MyTaq Mix (Bioline $\left.{ }^{\circledR}\right), 0.4 \mu$ l of each primer $(20 \mathrm{mM}), 2 \mu \mathrm{l}$ of DNA (20 ng), and $7.2 \mu \mathrm{l}$ of ultra-pure water were used in the final volume of $20 \mu \mathrm{l}$. Mycobacterium tuberculosis H37Rv DNA and water were used as positive and negative controls, respectively.

The genetic profile based on spoligotyping of each isolate was compared to those present in the international databases http://www.mbovis.org/ and http://www.pasteur-guadeloupe.fr: 8081/SITVITONLINE. The 24-MIRU-VNTR patterns were compared to those present in the MIRU-VNTRplus database deposited in the application: http://www.miru-vntrplus.org/ MIRU/index. The Hunter-Gaston discriminatory index (HGDI) was performed to evaluate the variability of the genotypes obtained by spoligotyping, and each of the alleles of 24-MIRUVNTR typing.

\section{RESULTS}

The 17 animals from which $M$. bovis was isolated came from 10 municipalities in the state of Pernambuco (Alagoinha, Bom Conselho, Chã Grande, Garanhuns, Ibirajuba, Jurema, Pedra, 
Pesqueira, Ribeirão, and Venturosa), which were mostly raised in the semi-intensive management system. These municipalities belong to three geographic regions of the state, namely, Southern Agreste, Central Agreste, and South Agreste. Among the animals diagnosed with the disease, females were the most affected $(16 / 17)$ and $64.7 \%(11 / 17)$ were older than 5 years; one calf 7 months old also yielded positive culture.

The clinical examination of cattle and buffaloes revealed apathy, lack of appetite, low body mass score, seromucous nasal discharge, dry cough, dyspnea, tachypnea, polyps, crackles, and areas of silence in the lung fields. Upon evaluation of the mammary gland, two (2/17) bovines were diagnosed with hypertrophied lymph nodes: one of these presented an enlarged posterior breast of firm consistency, hyperemia and hyperthermia, and physical changes in milk in one of the teats (lumps with serum). The other bovine had an anterior breast of firm consistency but with no visible changes of the milk. During rectal examination, some animals presented nodular structures of varying sizes and hardened consistency in the region of the mesentery, serous in the rumen, and uterus.

Macroscopic observation of lesions seen during postmortem examination revealed that $12 / 17$ animals (70.6\%) had miliary or protruding tuberculosis, distributed mainly in the lungs, mediastinal and tracheobronchial lymph nodes, liver, and mesenteric lymph nodes and less frequently in the kidneys, spleen, and greater omentum. Among the animals with generalized tuberculosis, two cattle also showed changes in the mammary gland and the uterus, characterized by granulomatous lesions with multifocal distribution and varied sizes, with areas of calcification and abscesses.

The granulomatous nodules observed in all animals were pleomorphic and had a caseous, thick, and yellowish content, with the formation of a fibrous capsule (Figure 1). In buffaloes, granulomas had a more whitish color when compared to cattle (Figure 2). In the young calf, in addition to lung lesions, small granulomas were observed in the central nervous system and lesions compatible with meningoencephalitis.

Histopathological analysis of the lesions revealed areas of central caseous necrosis and dystrophic calcification and intense inflammatory reaction in the regions adjacent to the necrosis areas, with a predominance of epithelioid macrophages and multinucleated giant cells, like Langhans.

Microbiological cultivation presented growth of colonies in $17 / 30$ (57\%) samples that were confirmed to be Mycobacterium spp. and more specifically $M$. bovis by molecular techniques. In three samples, presence of Trueperella pyogenes and, in a single animal, Nocardia spp. was encountered. Of the 17 bacterial growths, 14 were classified by the enzymatic restriction analysis of the gyrB gene as $M$. bovis. However, due to the importance of bacterial isolation, recognized as a gold standard test, the 17 samples were submitted to molecular genotyping techniques by Spoligotyping and 24-loci MIRU-VNTR.

Spoligotyping revealed five spoligotypes classified as belonging to $M$. bovis, including SB0121, SB0295, SB0852, SB0120, and a spoligotype that was not yet present in the database (Table 1).

The analysis of 24-loci MIRU-VNTR identified 13 genetic profiles from the 17 isolates of $M$. bovis from 14 properties in the state of Pernambuco (Table 1).
The analysis of the discriminatory power (HGDI) of MIRUVNTR in this study was higher, as expected, than Spoligotyping, respectively 0.980 and 0.713 . Distribution of the isolates according to the number of alleles in each locus and the analysis of the allelic diversity of the 24-loci is summarized in Table 2. Locus ETR A showed the highest discriminatory power $(h=$ 0.69), while five loci (ETR B, MIRU 16, ETR C, MIRU 27, and QUB 26) were classified as moderately discriminatory with $h$ between 0.33 and 0.58. Eight loci (MIRU 20, MIRU 26, Mtub 04, Mtub 29, QUB 11b, QUB 4156, Mtub 21, Mtub 39) presented low discriminatory power $(h \leq 0.27)$ while 10 loci showed absence of allelic diversity.

Isolates one and 10 showed failures in the amplification of some loci that are generally attributed to possible DNA mutations or degradation (5), thus preventing the primers from ringing. Given these results, the respective isolates started to be analyzed only in Spoligotyping, obtaining significant results.

\section{DISCUSSION}

It should be noted that the state of Pernambuco occupies a prominent place in milk production in the Northeast region, and the municipality of Garanhuns and its microregion are recognized as the state's milk basin (8). Dairy cattle and buffaloes are considered more vulnerable to $M$. bovis infection, as they have a longer life expectancy, stay longer on the properties, and are subjected to the rearing semi-intensive and intensive systems, very common in the region. During milking and other common management practices, animals cohabit, therefore increasing their likelihood of contact and the transmission of tuberculosis $(2,9)$, considered endemic in the State of Pernambuco $(2,10)$. The constant transit of animals between the properties within and between neighboring municipalities, the interstate cattle trade, and the absence of an effective sanitary control of the herds are factors that contribute to the spread of the disease in the region (2, 9).

In the present study, all animals presented clinical symptoms of tuberculosis with predominating respiratory impairment. In dairy farms, female animals generally remain for longer periods depending on the reproductive period, and this could be the main reason for having observed in this study the predominance of females over the age of 5 years to be exposed to M. bovis when compared to young cattle (9). Non-etheless, young animals also contract the infection and develop disease, as demonstrated by $M$. bovis isolation from a 7-month-old calf. The frequency of tuberculosis in cattle aged $<12$ months is generally associated with the ingestion of colostrum/milk from infected cows or transplacental infection $(11,12)$. The most evident clinical signs were observed in the advanced stages of the disease, as described by Izael et al. (10) and Waters (13), except for the calf that manifested the disease earlier in the form of cerebral tuberculosis combined with depression and paresis of the limbs. In addition to the predominant respiratory impairment in the animals in this study, two animals showed clinical changes in the mammary gland, resulting to be similar to that described by Waters (13). This observation reinforces the potential risk of the disease to 


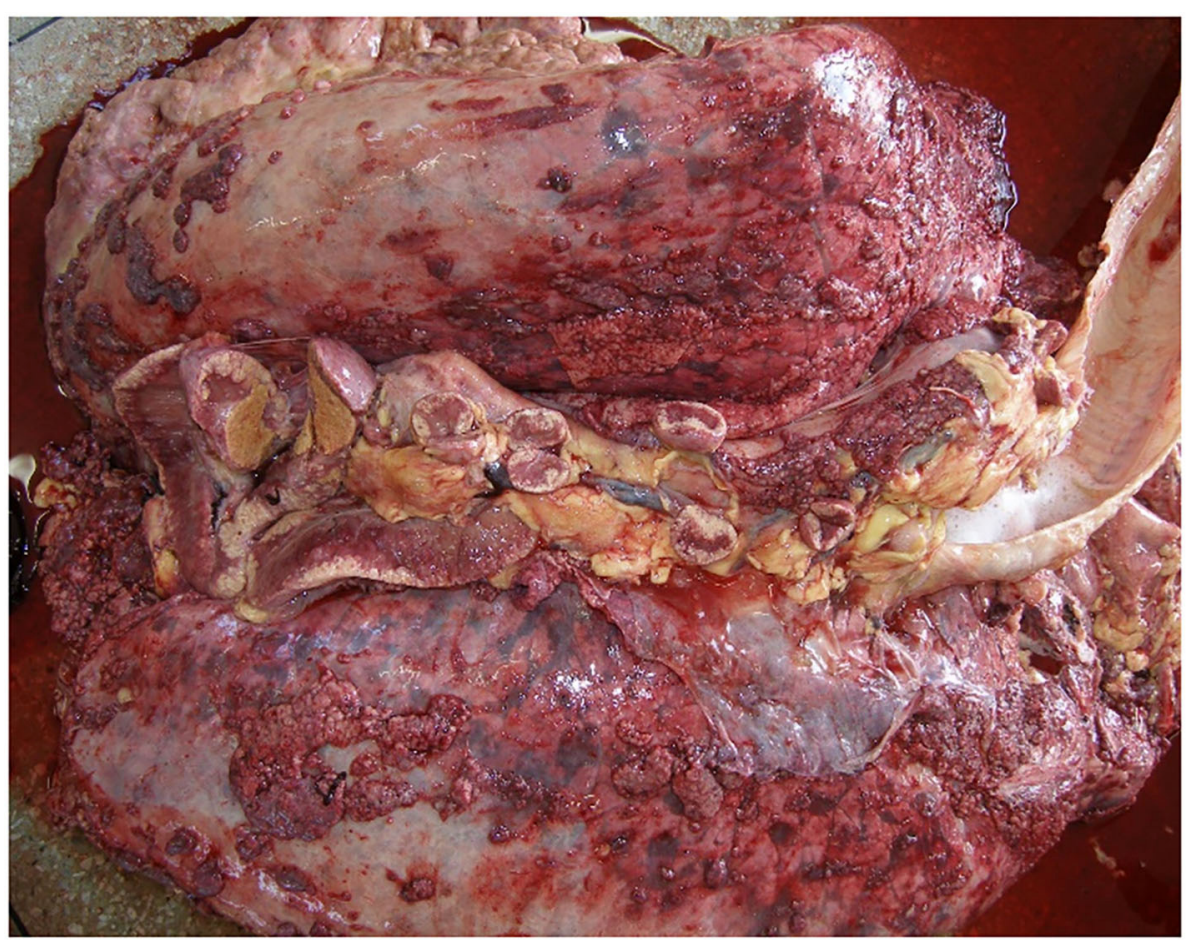

FIGURE 1 | Granulomatous lesions distributed in lung and mediastinal lymph nodes of bovines.

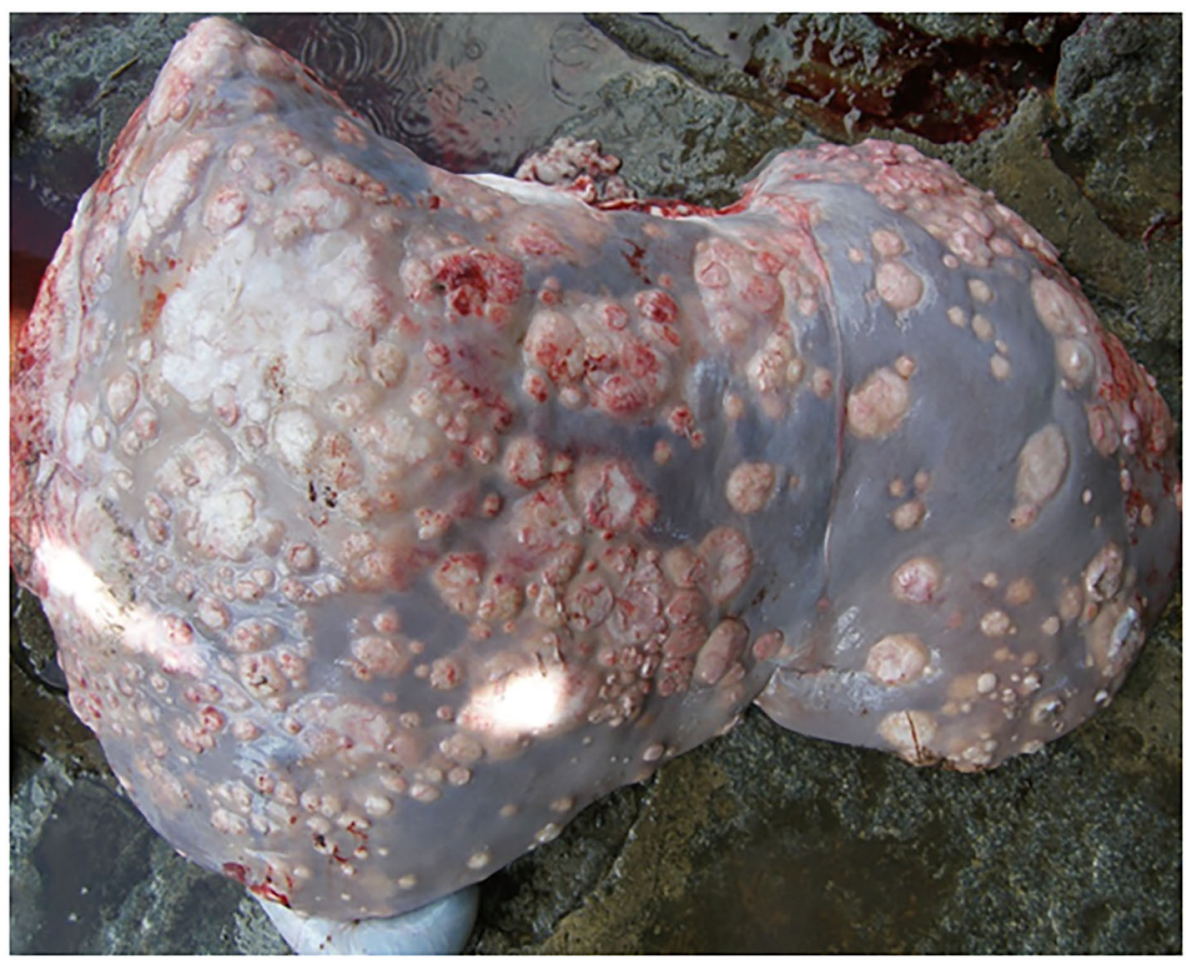

FIGURE 2 | Granulomatous lesions distributed in the liver of buffaloes. 
TABLE 1 | Molecular characterization of M. bovis isolates from cattle in the state of pernambuco by Spoligotyping and MIRU-VNTR.

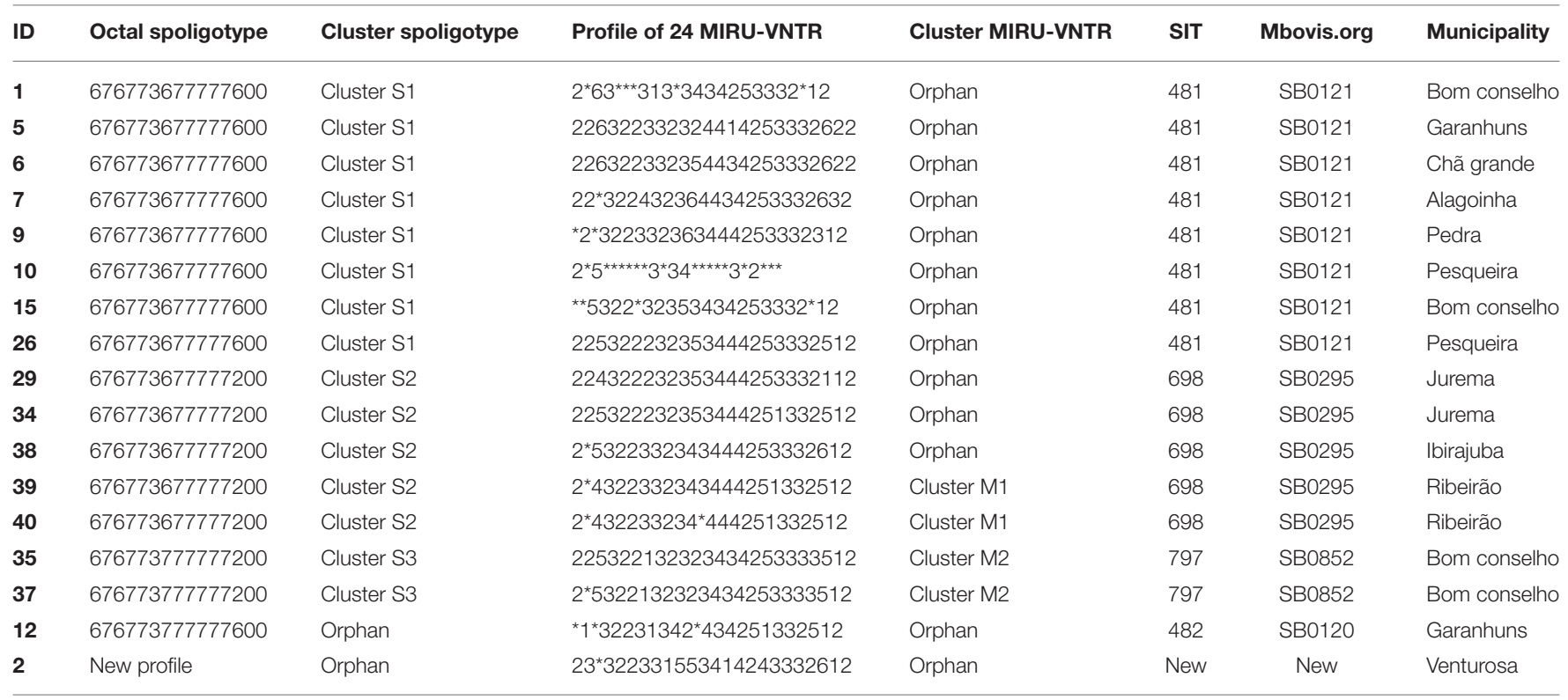

Cluster S - cluster Spoligotyping Cluster M - cluster MIRU-VNTR.

** Isolates that presented amplification failures in some loci.

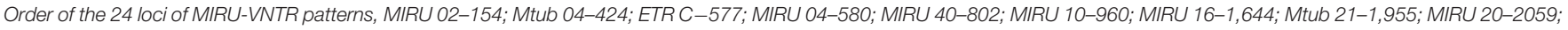

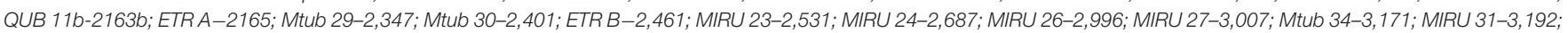
Mtub 39 - 3,690; QUB 26 - 4052; QUB 4,156-4,156; MIRU 3-4,348.

TABLE 2 | Distribution and allele diversity (HGDI) of the 24-loci MIRU-VNTR.

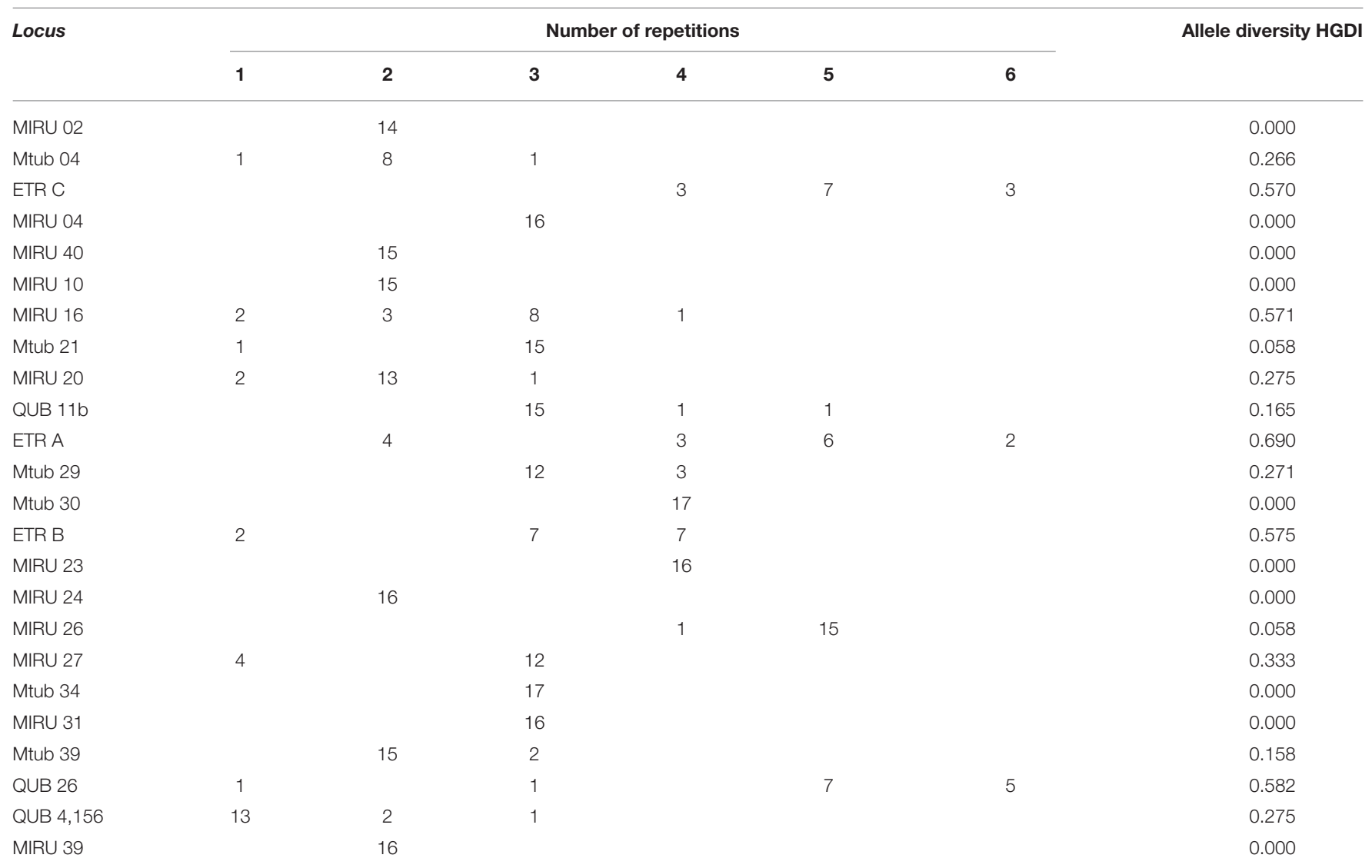


public health due to the consumption of raw milk and nonpasteurized derivatives, mainly observed in inland cities and rural areas, such as Garanhuns and the microregion (8).

The generalized form of the disease was predominant both in cattle and in the two buffaloes, with lesions that had disseminated to several organs. All animals had granulomatous injuries in the thoracic organs (lungs, pleura, tracheobronchial, and mediastinal lymph nodes), causing respiratory impairment. This result is similar to those described by Ramos et al. (14), who reported a higher prevalence of lesions compatible with tuberculosis in tracheobronchial and mediastinal lymph nodes and lungs; such typical predominance of lesions in the respiratory tract is indicative for airborne transmission. On the other hand, Alzamora Filho et al. (15) identified the most evident lesions in the lymph nodes of the head (retropharyngeal and parotid) with pulmonary parenchyma. These results corroborate with the findings of the present study, due to the typical predominance of lesions in the respiratory tract, suggesting the airway, as the main gateway for $M$. bovis in bovines. The lower occurrence of mesenteric lymph node involvement here observed was also described by Ramos et al. (14) and justified by the fact that oral route infection is secondary to the respiratory route in adult cattle.

The granulomatous lesions observed in the mammary gland and uterus common to two animals in this study reinforce the potential risk of transmission of $M$. bovis to humans due to the consumption of raw milk and its products $(16,17)$. On the other hand, the granulomatous lesions located in the central nervous system in young cattle are probably related to the ingestion of colostrum/milk from infected cows and can be justified by ascending infection via hematogenic route. This form of cerebral tuberculosis in cattle was also reported by Konradt et al. (11) and Silveira et al. (12).

The histopathological characterization of lesions present in granulomas was similar to the findings described by França et al. (18) who found in some samples a marked process of calcification with mineralization, differing from the lesions observed by Ramos et al. (14) and Silva et al. (19) who presented a more caseous aspect, suggesting that the animals that had been slaughtered were suffering from a recent infection or disease development.

The frequency of isolation of M. bovis, of 57\%, was observed presently in animals, with clinical tuberculosis. It has been described that some factors can interfere with the success of mycobacterial isolation and in particular of $M$. bovis, including the rigorous decontamination process of samples and the chronic character of the disease that confers intense calcification of the lesions, leading to low concentrations or absence of viable bacilli (20). This might have been influenced by the low isolation of $M$. bovis in the present sampling.

Besides Mycobacterium spp., we also observed bacteria belonging to other genera such as Trueperella pyogenes and Nocardia spp. It is worth mentioning that some microorganisms besides these, such as Actinomyces spp. and Actinobacillus spp., are also responsible for causing granulomatous lesions similar to tuberculosis lesions (21).
In the present study, 17 isolates compatible with Mycobacterium spp. were subjected to molecular diagnostics by RFLP of the gyrB gene. However, the analysis classified only $14 / 17$ isolates as M. bovis, different from the study carried out by Franco et al. (6) that obtained $100 \%$ compatibility between the isolation of Mycobacterium spp. and the gyrB analysis. The result obtained in the RFLP is probably related to factors that interfere with molecular tests, such as the presence of inhibitors of PCR reactions, low amount of viable bacilli due to chronic lesions, contaminants in the samples, and failures in extraction processing or DNA degradation (22).

Spoligotype SB0121, the most frequently encountered, was described as the most prevalent in national territory with a frequency of $29.1 \%$ in a study conducted in Latin American countries (23). The fact that we identified this spoligotype in the three defined geographical region studies here could be caused by the constant movement of animals, due to the practice of interstate cattle trade and also strongly suggestive for recent infections $(23,24)$.

The SB0295 profile was the second most prevalent spoligotype in this study (29\%) and has been referenced in Brazil with a prevalence of $24 \%$ (23). This is similar to that in the Midwest Region of the country, being identified in $16.2 \%$ of the total isolates (25). The two isolates identified in buffaloes as SB0295 were also recorded in the Amazon region in mixed buffalo and dairy cattle breeding areas under the same management condition as reported by Carneiro et al. (26). SB0295 was identified in buffaloe isolates in Argentina, highlighting the propagation of common M. bovis strains among bovines and buffaloes (23).

Spoligotype SB0852 was identified in two isolates. According to the international database, SB0852 has only been registered in Italy (27), suggesting a process of natural selection of these strains between geographic locations (25) or convergent evolution (23).

Finally, two spoligotypes were observed in this study single isolates only, with the case for SB0120 being similar to the low frequency of occurrence in other regions of the country $(6,23,28)$. The other was from a bovine that presented a spoligotype not present in the international database; this could be due to some microevolutionary events in the DR regions of a strain with an existing pattern (29).

In the region of development of the study, bovine tuberculosis is characterized as endemic, and the practice of commercialization and consumption of milk and fresh products increases the risk of zoonotic transmission, increasing the risk of sharing $M$. bovis isolates common among dairy cattle and the human population of the region, as previously recorded in other studies in different areas of the world. Genomic diversity in the M. tuberculosis complex remains a significant factor in the pathogenesis of tuberculosis, which can affect the virulence, transmissibility, host response, and drug resistance (29).

The genotyping performed in this study from the set of 24loci MIRU-VNTR is recommended for the comparative study of M. bovis profiles worldwide (5). Molecular genotyping identified 13 distinct genetic profiles, suggesting a diversity of $M$. bovis within and between the regions studied and considerable higher discriminatory power as compared to Spoligotyping. This is 
according to earlier results obtained both in Brazil (25) and in other countries. This demonstrated that although a large cluster was observed by spoligotyping alone, there exists genetic diversity among the strains of $M$. bovis in Pernambuco, probably due to the movement of animals between different regions, states, and rural properties $(23,25)$.

The analysis of allelic diversity of the different MIRUs are similar to those found by Souza Filho et al. (30) and Carvalho et al. (25) and demonstrating that for this MTBC species, only six of 24 loci allowed good discrimination, different from M. tuberculosis (31). The HGDI of 24-MIRU-VNTR and spoligotyping in this study was 0.980 and 0.713 , respectively, close to that observed by Carvalho et al. (25) with values 0.980 and 0.810 and the HGDI of 0.912 reported by Souza Filho et al. (30). Therefore, it seems that simultaneous consideration of both genotyping techniques for clustering might be more accurate for $M$. bovis transmission studies, also in the present study. However, the association between these techniques has been considered the best strategy for the molecular typing of $M$. bovis because they present better reproducibility and reliability, aiming at the analysis of strains mycobacterial (25).

This study is of great importance for the region as it is the first work carried out on molecular genotyping through the association between Spoligotyping and MIRUVNTR aiming at the molecular characterization of $M$. bovis isolates and identification of circulating genotypes in the state of Pernambuco. The importance of $M$. bovis as a cause of human tuberculosis is worth mentioning, although sometimes neglected, especially in developing countries. The consumption of raw milk and dairy products and the constant exposure to reservoir animals are considered the main risk factors in the epidemiological chain of infection.

\section{CONCLUSION}

The consumption of raw milk and dairy products is a frequent habit in the region, which, together with data on the occurrence of bovine tuberculosis, increases the risk of zoonotic transmission, alerting the possibility of sharing common M. bovis strains between dairy cattle and the population. The genotypic characterization allowed the identification of different $M$. bovis

\section{REFERENCES}

1. Cousins DV, Batisda R, Cataldi A, Quse V, Redrobe S, Dow S, et al. Tuberculosis in seals caused by a novel member of the Mycobacterium tuberculosis complex: Mycobacterium pinnipedii sp. nov. Int J Syst Evol Microbiol. (2003) 53:1305-14. doi: 10.1099/ijs.0.02401-0

2. Lima PRB, Nascimento DL, Almeida EC, Pontual KAQ, Amaku M, Dias RA, et al. Situação epidemiológica da tuberculose bovina no estado de Pernambuco, Brasil. Semina. (2016) 37:3601-10. doi: 10.5433/1679-0359.2016v37n5Supl2p3601

3. Drewe JA, Smith NH. Molecular epidemiology of Mycobacterium bovis. In: Thoen CO, Steele JH, Kaneene JB, editors. Zoonotic Tuberculosis: Mycobacterium Bovis and Other Pathogenic Mycobacteria. Chichester: John Wiley (2014). p. 79-88. doi: 10.1002/9781118474310.ch7 genotypes circulating in the state of Pernambuco, presenting both two large clusters by spoligotyping but evidencing considerable heterogeneity when using 24-MIRU-VNTR. Considering the diversity of genotypes obtained by combining spoligotyping and 24-MIRU-VNTR in the present setting, this methodology could be additive during transmission studies.

\section{DATA AVAILABILITY STATEMENT}

The original contributions presented in the study are included in the article/supplementary materials, further inquiries can be directed to the corresponding author/s.

\section{ETHICS STATEMENT}

The animal study was reviewed and approved by Animal Use Ethics Committee (CEUA), of the Federal Rural University of Pernambuco with license no. 09/2017 CEPE/ UFRPE in accordance with COBEA and National Institute of Health Guide for Care and Use of Laboratory Animals standards.

\section{AUTHOR CONTRIBUTIONS}

EM, CM, JA, MF, HL, and AP: conducted and performed the microbiological diagnostic design of mycobacterial culture procedures. HG, PS, CM, and JA: constructed the molecular diagnostic methodology. EM, HG, PS, IS, ML, and RF: conducted and performed the molecular tests of genotyping and molecular typing. EM, CM, HG, and PS: accurately reviewed the manuscript. All authors have read and approved the final version of the manuscript.

\section{ACKNOWLEDGMENTS}

We thank the Foundation for the Support of Science and Technology of the State of Pernambuco (FACEPE) for granting the scholarship (Process n. IBPG-1461-5.05/15) and Fernando José Paganini Listoni from the Department of Veterinary Hygiene and Public Health, Faculty of Veterinary Medicine and Animal Science - UNESP - Botucatu, São Paulo, for carrying out the microbiological cultivation. 
polymorphismanalysis. Mem Inst Oswaldo Cruz. (2004) 99:7458. doi: 10.1590/S0074-02762004000700014

8. Penaforte MA Jr, Borges JM, Azevedo DS, Borges-Filho EL. Perfil dos produtores de leite do município de Garanhuns. In: de Ensino J, Extensão PE, editors. Recife: UFRPE (2009). p. 1-3. Available online at: http://www. eventosufrpe.com.br/jepex2009/cd/resumos/R1002-2.pdf. (Accessed 02 Set, 2019)

9. Veloso FP, Baumgarten KD, Mota ALAA, Ferreira F, Neto JSF, GrisiFilho JHH, et al. Prevalence and herd-level risk factors of bovine tuberculosis in the State of Santa Catarina. Semina. (2016) 37:365972. doi: 10.5433/1679-0359.2016v37n5Supl2p3659

10. Izael MA, Silva STG, Costa NA, Souza JCA, Mendonça CL, Afonso JAB. Estudo retrospectivo da ocorrência dos casos de Tuberculose Bovina diagnosticados na Clínica de Bovinos de Garanhuns, PE de 2000 a 2009. Cienc Anim Bras. (2009) 1:452-7.

11. Konradt G, Bassuino DM, Bianchil MV, Bandinelli MB, Driemeier D, Pavarini SP. Neurotuberculosis in cattle in southern Brazil. Trop Anim Health Prod. (2016) 48:1089-94. doi: 10.1007/s11250-016-1048-z

12. Silveira AM, Nascimento EM, Konradt G, Neto EGM, Driemeier D. Galiza, GJN, et al. Tuberculosis of the central nervous system in cattle in Paraíba, Brazil. Pesq Vet Bras. (2018) 38:2092-8. doi: 10.1590/1678-5150-pvb-5976

13. Waters WR. Diseases of the respiratory system. In: Smith BP, editor. Large Animal Internal Medicine. St. Louis, MI: Elsevier (2015). p. 633-8.

14. Ramos JM, Heinemann MB, Neto JSF, Filho AFS, Cárdenas NC, Dantas AFM, et al. Isolation and identification of Mycobacterium bovis in bovines with positive reaction to the tuberculin test in the State of Paraíba, northeast Brazil. Arq Inst Biol. (2018) 85:1-7. doi: 10.1590/1808-1657000842016

15. Filho FA, Vasconcellos SEG, Gomes HM, Cavalcante MP, Suffys PN, Costa JN. Múltiplas estirpes de isolados de Mycobacterium bovis identificados por tipagem molecular em bovinos abatidos em matadouros-frigoríficos. Pesq Vet Bras. (2014) 34:103-8. doi: 10.1590/S0100-736X2014000200001

16. Cezar RDS, Silva NL, Borges JM, Santana VLA, Pinheiro JW Jr. Detection of Mycobacterium bovis in artesanal cheese in the state of Pernambuco, Brazil. Int J Mycobacteriol. (2016) 5:269-72. doi: 10.1016/j.ijmyco.2016.04.007

17. Siala M, Cassan C, Smaoui S, Kammoun S, Marouane C, Godreuil S, et al. A first insight into genetic diversity of Mycobacterium bovis isolated from extrapulmonary tuberculosis patients in South Tunisia assessed by Spoligotyping and MIRU-VNTR. Plos NeglTrop Dis. (2019) 13:119. doi: 10.1371/journal.pntd.0007707

18. França LR, Cruz JF, Neves VBF, Cerqueira RB. Prevalência e histopatologia de lesões sugestivas de tuberculose em carcaça de bovinos abatidos no Sudoeste da Bahia. Rev Bras Saúde Prod Anim. (2013) 14:72133. doi: 10.1590/S1519-99402013000400016

19. Silva DAV, Siconelli MJL, Bürger KP, Keid LB. Comparison between tests for tuberculosis diagnosis in slaughtered bovines. Arq Inst Biol. (2018) 85:15. doi: 10.1590/1808-1657000652016

20. Ambrosio SR, Oliveira EMD, Rodriguez CAR, Neto JSF, Amaku M. Comparison of three decontamination methods for Mycobacterium bovis isolation. Braz J Microbiol. (2008) 39:241-4. doi: 10.1590/S1517-83822008000200008

21. Mendes RE, Schneider AF, Werlich DE, Lucca NJ, Lorenzett MP, Pilati C. Estudo anatomopatológico em tecidos condenados pelo Serviço de Inspeção Federal (SIF) por suspeita de tuberculose. Cienc Anim Bras. (2013) 14:44853. doi: $10.5216 /$ cab.v14i4.8581

22. Carel C, Nukdee K, Cantaloube S, Bonne M, Diagne CT, Laval F, et al. Mycobacterium tuberculosis proteins involved in mycolic acid synthesis and transport localize dynamically to the old growing pole and septum. PLOS ONE. (2014) 9:1-15. doi: 10.1371/journal.pone.0097148
23. Zumárraga MJ, Arriaga C, Barandiaran S, Cobos-Marín L, Waard J, EstradaGarcia I, et al. Understanding the relationship between Mycobacterium bovis spoligotypes from cattle in Latin American Countries. Res Vet Sci. (2013) 94:9-21. doi: 10.1016/j.rvsc.2012.07.012

24. Rodríguez S, Romero B, Bezos J, Juan L, Álvarez J, Castellanos E, et al. Hight spoligotyping diversity within a Mycobacterium bovis population: clues to understanding the demography of the pathogen in Europe. Vet Microbiol. (2010) 141:89-95. doi: 10.1016/j.vetmic.2009. 08.007

25. Carvalho RCT, Vasconcellos SEG, Issa MA, Filho PMS, Mota PMPC, Araújo FR, et al. Molecular typing of Mycobacterium bovis from cattle reared in Midwest Brazil. PLoS ONE. (2016) 11:1-16. doi: 10.1371/journal.pone.0162459

26. Carneiro PAM, Pasquatti TN, Takatani H, Zumárraga MJ, Marfil MJ, Barnard C, et al. Molecular characterization of Mycobacterium bovis infection in cattle and buffalo in Amazon Region, Brazil. Vet Med Sci. (2019) 6:13341. doi: $10.1002 / \mathrm{vms} 3.203$

27. Boniotti MB, Goria M, Loda D, Garrone A, Benedetto A, Mondo A, et al. Molecular typing of Mycobacterium bovis strains isolated in Italy from 2000 to 2006 and evaluation of variable number tandem repeats for geographically optimized genotyping. J Clin Microbiol. (2009) 47:63644. doi: 10.1128/JCM.01192-08

28. Parreiras PM, Andrade GI, Nascimento TF, Oelemann MC, Gomes HM, Alencar AP, et al. Spoligotyping and variable number tandem repeat analysis of Mycobacterium bovis isolates from cattle in Brazil. Mem Inst Oswaldo Cruz. (2012) 107:64-73. doi: 10.1590/\$0074-0276201200010 0009

29. Adesokan HK, Streicher EM, Van Helden PD, Warren RM, Cadmus SIB. Genetic diversity of Mycobacterium tuberculosis complex strains isolated from livestock workers and cattle in Nigeria. PLoS ONE. (2019) 14:113. doi: 10.1371 /journal.pone. 0211637

30. Souza Filho AF, Osório ALAR, Jorge KSG, Araújo FR, Vidal CES, Araújo $\mathrm{CP}$, et al. Genetic profiles of Mycobacterium bovis from a cattle herd in southernmost Brazil. Semina. (2016) 37:3719-26. doi: 10.5433/1679-0359.2016v37n5Supl2p3719

31. Hilty M, Digimbaye C, Schelling E, Baggi F, Tanner M, Zinsstag J. Evaluation of the discriminatory power of variable number of tandem repeat (VNTR) typing of Mycobacterium bovis strains. Vet Microbiol. (2005) 109:21722. doi: $10.1016 /$ j.vetmic.2005.05.017

Conflict of Interest: The authors declare that the research was conducted in the absence of any commercial or financial relationships that could be construed as a potential conflict of interest.

Publisher's Note: All claims expressed in this article are solely those of the authors and do not necessarily represent those of their affiliated organizations, or those of the publisher, the editors and the reviewers. Any product that may be evaluated in this article, or claim that may be made by its manufacturer, is not guaranteed or endorsed by the publisher.

Copyright $(2021$ de Melo, Gomes, Suffys, Lopes, de Figueiredo Teixeira, dos Santos, Franco, Langoni, Paes, Afonso and de Mendonça. This is an open-access article distributed under the terms of the Creative Commons Attribution License (CC BY). The use, distribution or reproduction in other forums is permitted, provided the original author(s) and the copyright owner(s) are credited and that the original publication in this journal is cited, in accordance with accepted academic practice. No use, distribution or reproduction is permitted which does not comply with these terms. 